SOI: $1.1 /$ TAS $\quad$ DOI: $10.15863 /$ TAS

International Scientific Journal Theoretical \& Applied Science

p-ISSN: 2308-4944 (print) ｅ-ISSN: 2409-0085 (online)

Year: 2017 Issue: 04 Volume: 48

Published: $30.04 .2017 \quad \underline{\text { http://T-Science.org }}$

SECTION 9. Chemistry and chemical technology.
Igor Viktorovich Goloperov

Candidate of chemical sciences, Docent,

Department of Occupational Health and Environmental

Safety,

Ukrainian Engineering and Pedagogical Academy,

Ukraine goloperov_igor_viktorovich@ukr.net

Elena Aleksandrovna Belova

Candidate of chemical sciences, Docent,

Department of Occupational Health and Environmental

Safety,

Ukrainian Engineering and Pedagogical Academy,

Ukraine

belovaalena@meta.ua

Aleksandr Nikolaevich Baklanov

Doctor of chemical sciences, Professor,

Head of the Department of Occupational Health and

Environmental Safety,

Ukrainian Engineering and Pedagogical Academy,

Ukraine

baklanov227@mail.ru

Larisa Vladimirovna Baklanova

Candidate of chemical sciences, Docent,

Head of the Department of Occupational Health and

Environmental Safety,

Ukrainian Engineering and Pedagogical Academy,

Ukraine

baklanovalarisa@yandex.ua

\title{
SOLVING THE PROBLEMS OF SAFETY IN THE PRODUCTION OF IODIED SALT
}

Abstract: A solution to the problem of the safety of iodized salt is proposed. A new safe method of salt iodization has been developed. Toxic potassium iodated is suggested to be replaced with safer sodium iodide. To prevent the oxidation of sodium iodide with air oxygen, the technology of its introduction into the food emulsifier of MGD has been proposed. Sodium iodide was dissolved in ethanol by ultrasound to obtain 50-55\% solution. In the resulting solution, the food emulsifier MHD was dissolved to 50-60\% solution. The resulting iodine-containing additive was mixed with common salt. Shelf life of iodized salt is 2 years.

Key words: Safe iodized salt, sodium iodide, food emulsifier MGD.

Language: Russian

Citation: Goloperov IV, Belova EA, Baklanov AN, Baklanova LV (2017) SOLVING THE PROBLEMS OF SAFETY IN THE PRODUCTION OF IODIED SALT. ISJ Theoretical \& Applied Science, 04 (48): 70-75.

Soi: http://s-o-i.org/1.1/TAS-04-48-11 Doi: crossef https://dx.doi.org/10.15863/TAS.2017.04.48.11

\section{РЕШЕНИЕ ПРОБЛЕМ БЕЗОПАСНОСТИ ПРИ ПРОИЗВОДСТВЕ ЙОДИРОВАННОЙ ПОВАРЕННОЙ СОЛИ}

Аннотация: Предложено решение проблемы безопасности йодированной соли. Разработан новый безопасный способ йодирования соли. Токсичный йодат калия предложено заменить на безопасный йодид натрия. Для предотвращения окисления йодида натрия кислородом воздуха предложена технология его введения в пищевой эмульгатор МГД. Йодид натрия под действием ультразвука растворяли в этаноле для получения 50-55\% раствора. В полученном растворе растворяли пищевой эмульгатор МГД до 50 60\% раствора. Полученную йодсодержашую добавку смешивали с поваренной солью. Срок хранения йодированной соли 2 года.

Ключевые слова: Безопасная йодированная соль, йодид натрия, пищевой эмульгатор «МГД». 


\begin{tabular}{|c|c|c|c|c|c|c|}
\hline Impact Factor: & $\begin{array}{l}\text { ISRA (India) } \\
\text { ISI (Dubai, UAF } \\
\text { GIF (Australia) } \\
\text { JIF }\end{array}$ & $\begin{array}{l}=1.344 \\
=0.829 \\
=0.564 \\
=1.500\end{array}$ & $\begin{array}{l}\text { SIS (USA) } \\
\text { PИНЦ (Russia) } \\
\text { ESJI (KZ) } \\
\text { SJIF (Morocco) }\end{array}$ & $\begin{array}{l}=0.912 \\
=0.234 \\
=3.860 \\
=\mathbf{2 . 0 3 1}\end{array}$ & $\begin{array}{l}\text { ICV (Poland) } \\
\text { PIF (India) } \\
\text { IBI (India) }\end{array}$ & $\begin{array}{l}=6.630 \\
=1.940 \\
=4.260\end{array}$ \\
\hline
\end{tabular}

\section{Введение.}

Для профилактики йодного дефицита наиболее эффективным считается использование йодированной поваренной соли [1].

На Украине производство йодированной поваренной соли в промышленных масштабах осуществляется согласно ГОСТ 13830-97 (ДСТУ 3583-97) Соль поваренная пищевая. Общие технические условия введением йодата калия в количестве (40 $\square 15)$ г/т [1]. Недостатком такой соли является токсичность йодата калия $[2,3]$. При превышении допустимых концентраций йодат калия ухудшает состояние зрения, вплоть до отслоения сетчатки глаза [2]. Токсичность йодата калия требует крайне равномерного его распределения в пачке соли. Однако, последнее невозможно, так как вследствие микрокапиллярного эффектов йодат калия мигрируют из центра пачки соли к ее краям (30$50 \%$ йодата калия в зависимости от влаги соли и содержания примесей в течение трех месяцев) [4]. Готовый продукт - йодированная соль по ГОСТ 13830-97 имеет гарантованный срок хранения- 12 месяцев [1]. Однако, это соблюдается только при йодировании вакуумвыварочной поваренной соли, в остальных видах поваренной соли (каменной, садочной и самосадочной) наличие примесей восстановителей, приводит к восстановлению йодат-иона до йода и как результат - к потерям йода в течение 6-8 месяцев [4]. Следует также отметить, что йодат калия является сильным окислителем и в смеси с некоторыми органическими веществами способен образовывать взрывчатые смеси, что требует особых условий его хранения [5].

Нами ранее было предложено для получения безопасной йодсодержащей добавки применять смесь $40 \%$ спиртового раствора йодида натрия с расплавом пищевого эмульгатора «Моноглицериды дистиллированные» (МГД). Пищевой эмульгатор МГД широко применяется при производстве маргарина и относится к пищевым продуктам и не требует специального разрешения на применение в качестве пищевой добавки. При йодировании поваренной соли такой йодсодержащей добавкой, ее вводили в подогретую до температуры 70 - $83{ }^{\circ} \mathrm{C}$ поваренную соль с последующим перемешиванием. Однако, срок хранения такой соли не превышал 8 месяцев. Кроме того, технологический процесс приготовления такой соли был очень сложным из-за необходимости использования расплава пищевого эмульгатора МГД. Также, необходимо было использовать значительное количество эмульгатора МГД, не менее 2,5 г/кг поваренной соли [6] .
Данная работа посвящена получению безопасной йодированной поваренной соли с длительным сроком хранения. При этом в качестве основного йодсодержащего вещества использовали йодид натрия. Следует также отметить, что йодид натрия входит в перечень веществ, которые разрешается вводить в поваренную соли (перечень приведен в дополнении № 2 к межгосударственному стандарту ГОСТ 13830 -97«Соль поваренная. Общие технические условия).

\section{Экспериментальная часть}

При выполнении данной работы использовали ультразвуковой генератор типа 24УЗГИ-К-1,2 к которому подключали магнитострикционные и пьезоэлектрические излучатели, позволяющие создавать в исследуемых растворах ультразвуковые колебания частотой от 18 кГц до 2,5 МГц. Применяли стандартные пьезоэлектрические излучатели типа ЦТС-19, изготовленные из цирконата титана-свинца с защитным покрытием из фторопласта [79]. Данные пьезоэлектрические излучатели были выбраны потому, что имеют достаточную механическую прочность и стабильность излучения на высоких частотах УЗ (от 100 кГц до 2,5 МГц) при интенсивности до 12 Вт/см² [7-9]. Кроме того, использовали ультразвуковой диспергатор УЗДН - $1 \mathrm{M}$ с набором магнитострикционных излучателей, что позволяло создавать в исследуемой системе ультразвуковые колебания частотой от 16 кГц до 100 кГц при интенсивности ультразвука до 25 $\mathrm{BT} / \mathrm{cm}^{2}$. Также использовали типовую методику получения и исследования йодированной поваренной соли, предложенную ВНИИГалургии (Россия) [4].

Опыты проводили следующим образом. Предварительно готовили йодсодержащую добавку. Для этого растворяли йодид натрия в этаноле под действием УЗ частотой $18-160$ кГц, интенсивностью $00,05-0,45 \mathrm{BT} / \mathrm{cm}^{2}$ в течение 10 50 с. При этом получали $40-55 \%$ раствор йодида натрия в этаноле. В полученном растворе йодида натрия в этаноле растворяли эмульгатор МГД под действием У3 частотой 19-46 кГц, интенсивностью $0,05-0,40 \mathrm{BT} / \mathrm{cm}^{2}$ и УЗ частотой 0,5-3,0 МГц интенсивностью 0,45-0,76 Вт см ${ }^{2}$ в течение $0,1-3,6 \quad$ мин. Соответствующее количество приготовленной таким образом йодсодержащей добавки (содержание йодида натрия должен быть 20-44 мг/кг пробы поваренной соли, а эмульгатора МГД 1,00-2,50 г/кг пробы поваренной соли) смешивали с подогретой до температуры $70-83 \quad{ }^{\circ} \mathrm{C} \quad 1$ кг 


\begin{tabular}{|c|c|c|c|c|c|c|}
\hline Impact Factor: & $\begin{array}{l}\text { ISRA (India) } \\
\text { ISI (Dubai, UAF } \\
\text { GIF (Australia) } \\
\text { JIF }\end{array}$ & $\begin{array}{l}=1.344 \\
=0.829 \\
=0.564 \\
=1.500\end{array}$ & $\begin{array}{l}\text { SIS (USA) } \\
\text { PИНЦ (Russia) } \\
\text { ESJI (KZ) } \\
\text { SJIF (Morocco) }\end{array}$ & $\begin{array}{l}=0.912 \\
=0.234 \\
=\mathbf{3 . 8 6 0} \\
=\mathbf{2 . 0 3 1}\end{array}$ & $\begin{array}{l}\text { ICV (Poland) } \\
\text { PIF (India) } \\
\text { IBI (India) }\end{array}$ & $\begin{array}{l}=6.630 \\
=1.940 \\
=4.260\end{array}$ \\
\hline
\end{tabular}

поваренной соли. Каждую пробу полученной таким образом поваренной соли разделяли на две части. Одну часть вносли в эксикатор для проведения испытаний на слеживаемость эксикаторным методом [4], вторую - помещали в стандартную упаковку и через 9, 12, 18 и 24 месяца определяли содержание йода по стандартной методике [1].

\section{Результаты и их обсуждение}

В результате опытов установлено следующее. Растворения йодида натрия в этаноле под действием ультразвука частотой 100-150 кГц, интенсивностью $\quad 0,15-0,25 \quad \mathrm{~B} / \mathrm{cm}^{2} \quad$ позволяет увеличить растворимость йодида натрия в этаноле с $40 \%$ до 55\% (табл.1 - табл.3). Следует также отметить, необходимость использования йодида натрия, вместо йодида калия, связана с тем, что последний значительно лучше растворяется в этаноле[7, 10].

Использование одновременного действия ультразвука частотой 20-45 кГц, интенсивностью $0,10-0,35 \mathrm{BT} / \mathrm{cm}^{2}$ и ультразвука частотой $1,0-2,5$ МГц, интенсивностью $0,50-0,75 \mathrm{BT} / \mathrm{cm}^{2}$ в течение 0,5-3,0 мин позволяет проводить растворение эмульгатора МГД в 45 - 55\% спиртовом растворе йодида натрия (табл.4 - табл.7).

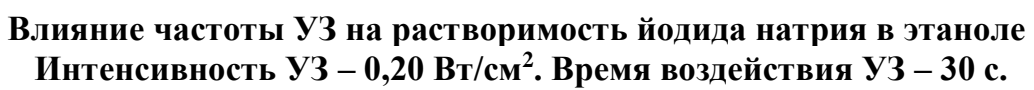

Таблица 1

\begin{tabular}{|l|c|c|c|c|c|c|c|c|c|c|}
\hline \multicolumn{1}{|c|}{ Характеристики } & \multicolumn{10}{|c|}{ Частота УЗ, кГЦ } \\
\cline { 2 - 11 } & Без УЗ & 18 & 98 & 100 & 120 & 130 & 140 & 150 & 155 & 160 \\
\hline $\begin{array}{l}\text { Растворимость } \\
\text { йодида натрия в } \\
\text { этаноле, г/100 мл }\end{array}$ & 40 & 40 & 42 & 50 & 52 & 53 & 55 & 55 & 45 & 42 \\
\hline
\end{tabular}

Влияние интенсивности УЗ на растворимость йодида натрия в этаноле

Таблица 2 Частота УЗ - 120 кГц. Время воздействия УЗ - 30 с.

\begin{tabular}{|l|c|c|c|c|c|c|c|c|c|c|}
\hline \multirow{2}{*}{ Характеристики } & \multicolumn{10}{|c|}{ Інтенсивність УЗ, Вт/см } \\
\cline { 2 - 11 } & Без У3 & 0,05 & 0,10 & 0,15 & 0,20 & 0,25 & 0,30 & 0,35 & 0,40 & 0,45 \\
\hline $\begin{array}{l}\text { Растворимость } \\
\text { йодида натрия в } \\
\text { этаноле, Г/100 мл }\end{array}$ & 40 & 40 & 42 & 53 & 55 & 56 & 56 & 55 & 44 & 42 \\
\hline
\end{tabular}

Таблица 3

Влияние времени воздействия УЗ на растворимость йодида натрия в этаноле Частота УЗ - 120 кГц. Интенсивность УЗ - 0,20 Вт/см².

\begin{tabular}{|l|c|c|c|c|c|c|c|c|c|c|}
\hline \multicolumn{1}{|c|}{ Характеристики } & \multicolumn{10}{|c|}{ Час дії У3, с } \\
\cline { 2 - 11 } & Без УЗ & 10 & 15 & 20 & 25 & 30 & 35 & 40 & 45 & 50 \\
\hline $\begin{array}{l}\text { Растворимость } \\
\text { йодида натрия в } \\
\text { этаноле, г/100 мл }\end{array}$ & 40 & 40 & 45 & 55 & 55 & 56 & 56 & 56 & 56 & 55 \\
\hline
\end{tabular}

Таблица 4

Влияние частоты высокочастотного УЗ на растворимость пищевого эмульгатора МГД в спиртовом растворе йодида натрия.

\begin{tabular}{|c|c|c|c|c|}
\hline \multirow{2}{*}{ Частота УЗ, МГц } & \multicolumn{4}{|c|}{$\begin{array}{c}\text { растворимость эмульгатора МГД, г/100 мл, в спиртовом } \\
\text { растворе йодида натрия, \% }\end{array}$} \\
\cline { 2 - 5 } & $40 \%$ & $45 \%$ & $50 \%$ & $55 \%$ \\
\hline 0,5 & 17 & 24 & 26 & 31 \\
\hline 1,0 & 22 & 56 & 58 & 59 \\
\hline 1,5 & 23 & 57 & 58 & 60 \\
\hline 2,0 & 22 & 56 & 50 & 62 \\
\hline 2,5 & 23 & 54 & 57 & 62 \\
\hline
\end{tabular}




\begin{tabular}{|c|c|c|c|c|}
\hline 3,0 & 12 & 31 & 36 & 38 \\
\hline $\begin{array}{c}\text { С УЗ только } \\
\text { низкой частоты }\end{array}$ & 0 & 0 & 0 & 0 \\
\hline
\end{tabular}

Частота низкочастотного интенсивность высокочастотного УЗ -0,60 Вm/ $\mathrm{cm}^{2}$. Время воздействия У3 - 1 мин.

Таблица 5

Влияние частоты низкочастотного УЗ на растворимость пищевого эмульгатора МГД в спиртовом растворе йодида натрия.

\begin{tabular}{|c|c|c|c|c|}
\hline \multirow{2}{*}{ Частота У3, кГц } & \multicolumn{4}{|c|}{ растворимость эмульгатора МГД, г/100 мл, в спиртовом } \\
& $40 \%$ & $45 \%$ & $50 \%$ & $55 \%$ \\
\cline { 2 - 5 } & 11 & 22 & 23 & 24 \\
\hline 19 & 22 & 54 & 56 & 57 \\
\hline 20 & 22 & 56 & 58 & 59 \\
\hline 22 & 21 & 55 & 57 & 60 \\
\hline 30 & 22 & 56 & 58 & 35 \\
\hline 45 & 14 & 31 & 0 & 0 \\
\hline С УЗ только & 0 & 0 & 33 & 0 \\
\hline
\end{tabular}

Частота высокочастотного УЗ 1,0 МГи. Интенсивность низкочастотного УЗ интенсивность высокочастотного УЗ -0,60 Вm/ $\mathrm{cm}^{2}$. Время воздействия УЗ - 1 мин.

\section{Влияние интенсивности УЗ на растворимость пищевого эмульгатора МГД в спиртовом}

Таблица 6 растворе йодида натрия.

\begin{tabular}{|c|c|c|c|c|c|c|}
\hline \multirow{2}{*}{$\begin{array}{c}\text { Интенсивность } \\
\begin{array}{c}\text { низкочастотного } \\
\text { У3, Вт/см }\end{array}\end{array}$} & 0,45 & 0,50 & 0,60 & 0,40 & 0,75 & 0,76 \\
\cline { 2 - 7 } & 24 & 28 & 26 & 27 & 23 & 22 \\
\hline 0,05 & 33 & 56 & 57 & 57 & 56 & 30 \\
\hline 0,10 & 32 & 57 & 58 & 59 & 58 & 30 \\
\hline 0,20 & 31 & 57 & 60 & 60 & 59 & 34 \\
\hline 0,35 & 30 & 32 & 32 & 34 & 33 & 31 \\
\hline 0,40 & & \multicolumn{5}{|c|}{ Интенсивность У3 высокой частоты, Вт/см ${ }^{2}$} \\
\hline
\end{tabular}

Частота низкочастотного УЗ - 22 кГи, частота высокочастотного УЗ - 1 МГй. Время воздействия УЗ 1 мин. Использован $50 \%$ спиртовый раствор йодида натрия.

Следует также отметить, что использование ультразвука только одной низкой или только одной высокой частоты не приводит к растворению эмульгатора МГД в спиртовом растворе йодида натрия (табл. 4, табл.5).
Очевидно, это связано с соответствующими структурными изменениями раствора под воздействием УЗ данных параметров [7, 11].

Таблиця 7

\section{Влияние времени воздействия УЗ на растворимость пищевого эмульгатора МГД в спиртовом} растворе йодида натрия.

\begin{tabular}{|l|c|c|c|c|c|c|c|c|c|c|}
\hline \multirow{2}{*}{ Характеристики } & \multicolumn{9}{|c|}{ Время воздействия УЗ, мин } \\
\cline { 2 - 10 } & Без УЗ & 0 & 0,1 & 0,2 & 0,5 & 1,0 & 2,0 & 3,0 & 3,5 & 3,6 \\
\hline $\begin{array}{l}\text { Растворимость } \\
\text { эмульгатора МГД, } \\
\text { г/100 мл }\end{array}$ & Не растворяется & 40 & 41 & 42 & 55 & 58 & 59 & 58 & 56 & 51 \\
\hline
\end{tabular}

Частота низкочастотного УЗ - 22 кГи, частота высокочастотного УЗ - 1 МГц. Интенсивность низкочастотного УЗ - 0,20 Вm/ $\mathrm{cm}^{2}$, интенсивность высокочастотного УЗ - 0,60 Вт/см ${ }^{2}$.Использован 50 \% спиртовый раствор йодида натрия. 


\begin{tabular}{l|lr|ll|ll} 
& ISRA (India) & $=\mathbf{1 . 3 4 4}$ & SIS (USA) & $=\mathbf{0 . 9 1 2}$ & ICV (Poland) & $\mathbf{= 6 . 6 3 0}$ \\
Impact Factor: & ISI (Dubai, UAE) $=\mathbf{0 . 8 2 9}$ & PUHL (Russia) $=\mathbf{0 . 2 3 4}$ & PIF (India) & $=\mathbf{1 . 9 4 0}$ \\
& GIF (Australia) & $=\mathbf{0 . 5 6 4}$ & ESJI (KZ) & $=\mathbf{3 . 8 6 0}$ & IBI (India) & $=\mathbf{4 . 2 6 0}$
\end{tabular}

В табл. 8 приведено сравнение методов получения йодированной поваренной соли, известного [6] и предлагаемого. Как следует из данных, приведенных в табл. 8, использование предлагаемого метода позволяет увеличить срок хранения йодированной соли до 2-х лет, при этом количество необходимого эмульгатора МГД может быть уменьшено с 2,5 до 1,0 г/кг пробы соли. Также следует отметить, что при использовании данного метода получения йодированной поваренной соли увеличивается до 2-х лет не только сохранность йода, но и уменьшается слеживаемость поваренной соли. То есть, использование данного метода позволяет уменьшить слеживаемость готового продукта (сопротивление сжатию считается допустимым

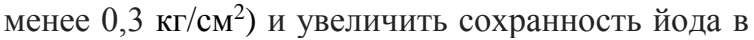
йодированной поваренной соли до 2 лет.

\section{Выводы}

Таким образом, проведенные исследования показали, что использование ультразвука при приготовлении йодсодержащей добавки раствора йодида натрия в эмульгаторе МГД позволяет увеличить срок хранения йодированной поваренной соли до 2-х лет. При этом используются безопасные компоненты: йодид натрия, этанол и эмульгатор МГД (относится к пищевым веществам и используется при приготовлении маргаринов).

Таблица 8

Сравнение методов получения безопасной йодированной соли по [6] и предлагаемого.

\begin{tabular}{|c|c|c|c|c|c|c|c|c|c|c|}
\hline \multirow[b]{2}{*}{$\begin{array}{c}\text { № } \\
\text { проб } \\
\text { Ы }\end{array}$} & \multirow{2}{*}{$\begin{array}{c}\text { Вве- } \\
\text { дено } \\
\mathrm{NaJ}, \\
\text { мг/кг } \\
\text { пробы }\end{array}$} & \multirow{2}{*}{$\begin{array}{c}\text { Введено } \\
\text { эмульга- } \\
\text { тора } \\
\text { МГД, } \\
\text { г/кг про- } \\
\text { бы }\end{array}$} & \multicolumn{4}{|c|}{ Найдено $\mathrm{NaJ}$, мг/кг пробы } & \multicolumn{4}{|c|}{ Сопротивление сжатию, кг/см² } \\
\hline & & & $\begin{array}{c}9 \\
\text { месяцев }\end{array}$ & $\begin{array}{c}12 \\
\text { меся } \\
\text { цев }\end{array}$ & $\begin{array}{c}18 \\
\text { меся- } \\
\text { цев }\end{array}$ & $\begin{array}{c}24 \\
\text { меся- } \\
\text { ца }\end{array}$ & \begin{tabular}{c}
9 \\
\multicolumn{1}{c}{9} \\
меся- \\
цев
\end{tabular} & $\begin{array}{c}12 \\
\text { меся- } \\
\text { цев }\end{array}$ & $\begin{array}{c}18 \\
\text { меся- } \\
\text { цев }\end{array}$ & $\begin{array}{c}24 \\
\text { месяца }\end{array}$ \\
\hline \multicolumn{11}{|c|}{ Метод согласно [6] } \\
\hline 1 & 20 & 1,00 & 16,4 & 14,7 & 10,1 & 2,4 & 1,05 & 1,43 & 2,48 & 3,97 \\
\hline 1 & 36 & 1,00 & 29,1 & 23,8 & 18,4 & 3,9 & 1,06 & 1,37 & 2,32 & 3,12 \\
\hline 1 & 44 & 1,00 & 35,1 & 28,2 & 20,3 & 4,8 & 1,08 & 1,29 & 2,12 & 3,04 \\
\hline 2 & 20 & 2,00 & 18,4 & 17,8 & 11,2 & 2,9 & 0,11 & 0,28 & 1,67 & 2,05 \\
\hline 2 & 36 & 2,00 & 33,0 & 30,1 & 19,0 & 4,5 & 0,09 & 0,22 & 1,45 & 1,98 \\
\hline 2 & 44 & 2,00 & 40,0 & 34,6 & 22,3 & 5,3 & 0,08 & 0,26 & 1,40 & 1,87 \\
\hline 3 & 20 & 2,50 & 19,6 & 19,6 & 11,9 & 3,2 & ${ }^{*}-$ & 0,11 & 1,65 & 2,03 \\
\hline 3 & 36 & 2,50 & 35,2 & 34,9 & 19,5 & 4,8 & *- & 0,10 & 1,64 & 1,95 \\
\hline 3 & 44 & 2,50 & 42,7 & 40,1 & 22,9 & 6,0 & *- & 0,09 & 1,59 & 1,92 \\
\hline \multicolumn{11}{|c|}{ Предлагаемый метод } \\
\hline 1 & 20 & 0,50 & 17,5 & 17,0 & 15,1 & 12,3 & 0,11 & 0,28 & 1,03 & 2,12 \\
\hline 1 & 36 & 0,50 & 33,2 & 33,9 & 18,4 & 14,7 & 0,09 & 0,21 & 1,05 & 2,12 \\
\hline 1 & 44 & 0,50 & 38,7 & 38,2 & 25,3 & 21,3 & 0,08 & 0,23 & 1,05 & 2,14 \\
\hline 2 & 20 & 1,00 & 19,7 & 19,4 & 17,2 & 11,5 & ${ }^{*}-$ & ${ }^{*}-$ & 0,11 & 0,28 \\
\hline 2 & 36 & 1,00 & 35,9 & 35,2 & 32,0 & 29,5 & ${ }^{*}-$ & *- & 0,09 & 0,27 \\
\hline 2 & 44 & 1,00 & 44,0 & 43,8 & 40,3 & 35,3 & *- & *- & 0,10 & 0,28 \\
\hline 3 & 20 & 1,50 & 19,9 & 19,7 & 18,7 & 18,2 & *- & *- & ${ }^{*}-$ & 0,11 \\
\hline 3 & 36 & 1,50 & 35,8 & 35,6 & 33,8 & 32,3 & ${ }^{*}$ & ${ }^{*}$ & *- & 0,09 \\
\hline 3 & 44 & 1,50 & 43,4 & 42,9 & 40,7 & 36,0 & ${ }^{*}$ & ${ }^{*}$ & ${ }^{*}-$ & 0,09 \\
\hline
\end{tabular}




\begin{tabular}{l|lrl|l|ll} 
& ISRA (India) & $=\mathbf{1 . 3 4 4}$ & SIS (USA) & $=\mathbf{0 . 9 1 2}$ & ICV (Poland) & $=\mathbf{6 . 6 3 0}$ \\
Impact Factor: & ISI (Dubai, UAE) $=\mathbf{0 . 8 2 9}$ & PUHL (Russia) $=\mathbf{0 . 2 3 4}$ & PIF (India) & $=\mathbf{1 . 9 4 0}$ \\
& GIF (Australia) & $\mathbf{0 . 5 6 4}$ & ESJI (KZ) & $=3.860$ & IBI (India) & $=\mathbf{4 . 2 6 0}$ \\
& JIF & $\mathbf{1 . 5 0 0}$ & SJIF (Morocco) & $=\mathbf{2 . 0 3 1}$ & & \\
\hline
\end{tabular}

\section{References:}

1. (1997) GOST 13830-97 (DSTU 3583-97) Sol' povarennaya pishchevaya. Obshchiye tekhnicheskiye usloviya

2. Potts AM (1996) Toxic responses of the eye. In: Klaassen CD (ed) Casarett and Doull's Toxicology, Mc Graw Hill, New York, 1996, p. $601-602$.

3. Singalavanija A, Dongosintr N, Dulayajinda D (1994) Potassium iodate retinopathy. Acta Ophthalmol (Copenh), 1994, v.72, p.513 - 519.

4. Furman AA, Bel'dy MP, Sokolov ID (1989) Povarennaya sol'. Proizvodstvo i primeneniye v khimicheskoy promyshlennosti.-M.: Khimiya, 1989.- 272 p.

5. Remi G (1963) Kurs neorganicheskoy khimii. T. 1.- M.: izd-vo inostrannoy litera-tury, 1963.$920 \mathrm{p}$

6. Matveyeva TA, Baklanov AN, Selitrennikov YG (1989) Sposob iodirovaniya povarennoy soli - A.s. № 1491811, SSSR- Opubl. 07.07.89- Byul. № 25 .

7. (2012) Ul'trazvuk $\mathrm{v}$ analiticheskoy khimii i khimicheskoy tekhnologi: monografiya / A.N.
Baklanov, A.P. Avdeyenko, S.A. Konovalova, L.V. Baklanova . - Kramatorsk: DGMA, 2012. $-332 \mathrm{p}$.

8. Goloperov IV, Belova EA, Baklanov AN (2016) ULTRASOUND IN THE DETERMINATION CESIUM AND CESIUM137 IN HIGHLY WATERS, BRINE AND SALT/ // «Theoretical \& Applied Science. 2016. -V. 33.- № 1. - p. 64-68.

9. Yurchenko OI, Baklanov AN, Belova EA, Kalinenko OS, Baklanova LV (2015) ULTRASOUND TO INTENSIFY OF FOOD DRY MINERALIZATION BY THE OXIDANTS IN VAPOR FORM / // «Theoretical \& Applied Science. - 2015. V.27.- № 7. - p. 122-129.

10. Lur'ye YY (1971) Spravochnik po analiticheskoy khimii.-M.:Khimiya, 1971.- 456 p.

11. Margulis MA (1986) Zvukokhimicheskiye reaktsii i sonolyuminestsentsiya. - M.: Khimiya, 1986. - 288 p. 